\title{
Potential of Phosphate Solubilizing Microorganisms for Efficient Phosphate Utilization with Eppawala Rock Phosphate : A Review
}

\author{
Jayaneththi J.P.H.U. \\ Department of Agricultural Engineering and Soil Science, Rajarata University of Sri Lanka \\ harshaniupulika@gmail.com
}

\begin{abstract}
Phosphorus $(\mathrm{P})$ is a vital element in crop nutrition. In most soil, $\mathrm{P}$ remains as insoluble and only less than $10 \%$ is available for plants due to high $\mathrm{P}$ fixation. Phosphate solubilizing microorganisms (PSM) are capable of dissolving insoluble forms of phosphates into plant available forms. Triple Super Phosphate (TSP) is commonly used source of P fertilizer for many crops in Sri Lanka. However, TSP applied fields in Sri Lanka has recorded notable contents of certain heavy metals such as cadmium and arsenic. Eppawala Rock Phosphate (ERP) is a cheap, phosphate-rich source but due to its low solubility usages are limited for annual crops as a P fertilizer. However, PSM have shown the capability of solubilizing ERP and supplying P to plants. At present, several research studies pertaining to the application of PSM as inoculum for crops were condcuted. Hence this review based study is focused in identify the potential of PSM in agriculture. Literature reveled that PSM have shown their potential knack on solubilizing P in ERP with producing clear halo zones and organic acids proportionally. Thus more research studies have to be undertaken under field condition in order to optimize PSM innocula with ERP.
\end{abstract}

Keywords: Halo zones, Eppawala rock phosphate, Organic acids, Phosphorous, Phosphate solubilizing microorganisms 